Supporting Information for

\title{
Synthesis and easy functionalization of highly porous networks through exchangeable fluorines for target specific applications
}

Damien Thirion ${ }^{1}$, Yonghyun Kwon ${ }^{2}$, Vepa Rozyyev ${ }^{1}$, Jeehye Byun ${ }^{1}$, Cafer T. Yavuz ${ }^{1,2 *}$

${ }^{1}$ Graduate School of EEWS, and ${ }^{2}$ Department of Chemistry, KAIST, Daejeon, 305-701 Korea, yavuz@kaist.ac.kr

Content

- MATERIALS AND METHODS

- EXPERIMENTAL PROCEDURES

- SCHEME S1. STRATEGIES TO ACCESS C-C BONDED FLUORINATED POROUS NETWORKS.

- SCHEME S2: MODEL REACTION PERFORMED BY WATSON ET AL. WITH ISOLATED YIELDS

- SCHEME S3: EXPANDED DETAILS ON THE CHEMICAL REACTION FOR THE COP-175 SYNTHESIS AND MODIFICATION.

- FIGURE S1: XRD DIFFRACTION PATTERN OF COP-175

- FIGURE S2: TGA OF COP-175 AND COP-175-MEO IN NITROGEN ATMOSPHERE

- FIGURE S3: FTIR SPECTRA OF COP-175 (BLACK) AND COP-175-MEO (RED).

- FIGURE S4: SEM IMAGES OF COP-175 AT $5 \mu M, 1 \mu M$ AND 500 NM MAGNIFICATION 


\section{MATERIALS AND METHODS}

Hexafluorobenzene and dry Toluene were obtained from Sigma-Aldrich, (Trimethylsily)acetylene, 1Phenyl-2-Trimethylsilylacetylene were obtained from Alfa Aesar. TransDichlorobis(triphenylphosphine)palladium(II) was obtained from Strem chemicals. Tetrabutylammonium fluoride (1M in THF) was obtained from TCI Japan. All other chemicals and solvents were obtained from Samchun Pure Chemicals, Korea and used without further purification unless otherwise specified. XPS (X-ray Photoelectron Spectroscopy) spectra were obtained using a Thermo VG Scientific Sigma Probe system equipped with an Al-K $\alpha$ X-ray source with an energy resolution of $0.47 \mathrm{eV} \mathrm{FWHM} \mathrm{under} \mathrm{UHV}$ conditions of $10^{-10}$ Torr. ${ }^{13} \mathrm{C}$ solid-state NMR was performed on a Brucker Digital AVANCE HD 400WB spectrometer at $400 \mathrm{MHz}$. The spectrometer was equipped with a $4 \mathrm{~mm}$ probe. ${ }^{13} \mathrm{C}$ NMR spectra were recorded with a $\pi / 2$ pulse width of $3.8 \mu$ s and a delay of $10 \mathrm{~s} .{ }^{13} \mathrm{C}$ chemical shift was calibrated indirectly using ${ }^{13} \mathrm{C}$-labeled glycine as an external reference. ${ }^{19} \mathrm{~F}$ Solid-state NMR was performed at the KAIST Central Research Instrument Facility on an Agilent $400 \mathrm{MHz} 54 \mathrm{~mm}$ DD2 equipped with a HFXY $1.6 \mathrm{~mm}$ probe. The contact time was $5 \mathrm{~ms}$ with a delay of $10 \mathrm{~s}$. Samples were spun at $12 \mathrm{kHz}$ for ${ }^{13} \mathrm{C}$ and $32 \mathrm{kHz}$ for ${ }^{19} \mathrm{~F}$. Infrared spectra (FT-IR) were recorded at KAIST energy and environment research center with a Jasco FT/IR-4100 type-A spectrometer using $\mathrm{KBr}$ pellets. Thermogravimetric analyses were performed on a Shimadzu DTG-60A by heating the samples up to $800{ }^{\circ} \mathrm{C}$ at a rate of $10{ }^{\circ} \mathrm{C} \mathrm{min}{ }^{-1}$ under nitrogen or air atmosphere. The surface morphology of powder was examined by a scanning electron microscope (Magellan 4000). Powders were coated with a $1 \mathrm{~nm}$ osmium layer prior to measurement. Textural characterization of polymers was carried out from argon adsorption isotherms using a Micromeritics 3FLEX accelerated surface area and porosimetry analyzer at $87 \mathrm{~K}$. Prior to measurement, samples were degassed at $423 \mathrm{~K}$ for $5 \mathrm{~h}$ under vacuum. The specific surface areas were derived from Brunauer-EmmettTeller (BET) method. Pore size distribution was calculated with the Micromeritics 3FLEX software using a 2D-NLDFT model assuming finite carbon slit pores (argon model 87K, Aspect ratio 4). This model was chosen as it gave the best fit between experiment and calculation.

\section{EXPERIMENTAL PROCEDURES}

\section{Synthesis of Tetra(4-(2-(trimethylsilyl)ethynyl)phenyl)methane}

Tetra(4-(2-(trimethylsilyl)ethynyl)phenyl)methane was synthesized according to reported procedures and recrystallized from chloroform/hexane prior to use. ${ }^{\mathrm{S} 1}$

\section{Synthesis of COP-175}

Tetra(4-(2-(trimethylsilyl)ethynyl)phenyl)methane (352 mg, $0.5 \mathrm{mmol})$ and Hexafluorobenzene $(116 \mu \mathrm{L}$, $1 \mathrm{mmol})$ were dissolved in dry toluene $(25 \mathrm{~mL})$ at room temperature under nitrogen.

Tetrabutylammonium fluoride $0.1 \mathrm{M}(100 \mu \mathrm{L}, 0.01 \mathrm{mmol})$ was added dropwise to the transparent solution which quickly darkens from yellow to dark brown. The mixture was left to stir at room temperature overnight. Methanol $(20 \mathrm{~mL})$ was added, the polymer filtered out and Soxhlet extracted for $24 \mathrm{~h}$ with THF. COP-175 was dried at $100^{\circ} \mathrm{C}$ for $18 \mathrm{~h}$ and obtained as a dark red-brown powder $(255 \mathrm{mg}, 72 \%)$.

\section{Synthesis of COP-175-MeO}

COP-175 (150 mg) was dispersed in DMF (10 mL). Sodium methoxide $(150 \mathrm{mg})$ was added and the mixture was stirred at $80^{\circ} \mathrm{C}$ for $24 \mathrm{~h}$. Water was added and the solid was filtered off. The solid was washed extensively with dilute $\mathrm{HCl}, \mathrm{MeOH}$ and THF until the filtrate becomes neutral. COP-175-MeO was dried at $120^{\circ} \mathrm{C}$ for $18 \mathrm{~h}$ and obtained as a red-brown powder $(136 \mathrm{mg}, 90 \%)$. 
<smiles>[X]c1c(F)c(F)c([X])c(F)c1F</smiles>

C-C coupling

by metal catalyzed

reactions

Core: Ar-Y

\section{Linker}

$\mathrm{X}=\mathrm{Br}, \mathrm{I}$
Ar-Y Catalyst, Base

Sonogashira: $-\mathrm{C}=\mathrm{C}-\mathrm{H}, \mathrm{Pd}\left(\mathrm{PPh}_{3}\right)_{2} \mathrm{Cl}_{2}, \mathrm{Cul}, \mathrm{Et}_{3} \mathrm{~N}$

Suzuki: $\quad-\mathrm{B}(\mathrm{OH})_{2}, \mathrm{PdCl}_{2} \mathrm{dppf}, \mathrm{CsCO}_{3}$

Stille: $\quad-\mathrm{SnBu}_{3}, \mathrm{Pd}\left(\mathrm{PPh}_{3}\right)_{4}$

Negishi: $\quad-\mathrm{MgBr}, \quad \mathrm{ZnCl}_{2}, \mathrm{P}\left(\mathrm{Cy}_{3}\right)_{2}$, Lil

Hiyama: $\quad-\mathrm{SiH}_{3}, \quad \mathrm{Pd}$

Kumada: $\quad-\mathrm{MgBr}, \quad \mathrm{NiCl}_{2} \mathrm{dppp}$<smiles>[R]c1c(F)c(F)c([R])c(F)c1F</smiles>

Core formation

by cyclization
$\mathrm{R}=\mathrm{CN}, \mathrm{C} \equiv \mathrm{CH}, \mathrm{COMe}$ *

High temperature molten $\mathrm{ZnCl}_{2}$ or Diels-Alder at $180^{\circ} \mathrm{C}$

*no known fluorine tolerance<smiles>CCc1c(F)c(F)c(CC)c(F)c1F</smiles>

Fluorinated Porous Network
This work<smiles>Fc1c(F)c(F)c(F)c(F)c1F</smiles>

Linker

riner
Core: $\mathrm{Ar}-\mathrm{C} \equiv \mathrm{C}-\mathrm{TMS}$

RT catalytic TBAF

Scheme S1. Strategies to access C-C bonded fluorinated porous networks.<smiles>Fc1c(F)c(F)c(F)c(F)c1F</smiles><smiles>Fc1c(F)c(C#Cc2ccccc2)c(F)c(F)c1C#C[PH2+]c1ccccc1</smiles>

$81.3 \%$

$8.4 \%$<smiles></smiles>

$4.6 \%$<smiles>Fc1c(F)c(F)c(C#Cc2ccccc2)c(F)c1F</smiles>

$3.9 \%$<smiles>Fc1c(C#Cc2ccccc2)c(F)c(C#Cc2ccccc2)c(F)c1C#Cc1ccccc1</smiles>

$1.8 \%$

Scheme S2: Model reaction performed by Watson et al. with isolated yields ${ }^{\text {S2 }}$ 


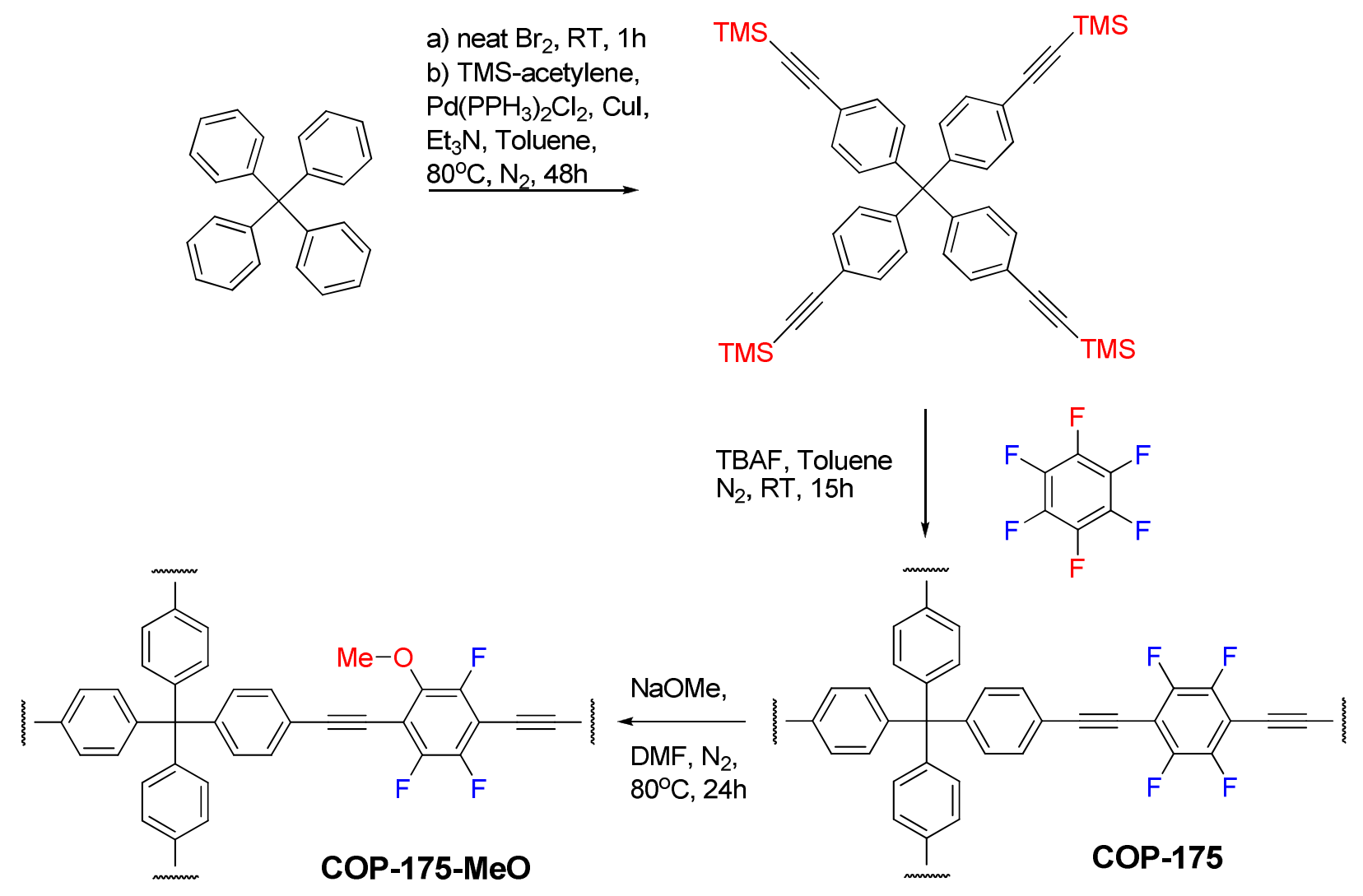

Scheme S3: Expanded details on the chemical reaction for the COP-175 synthesis and modification.

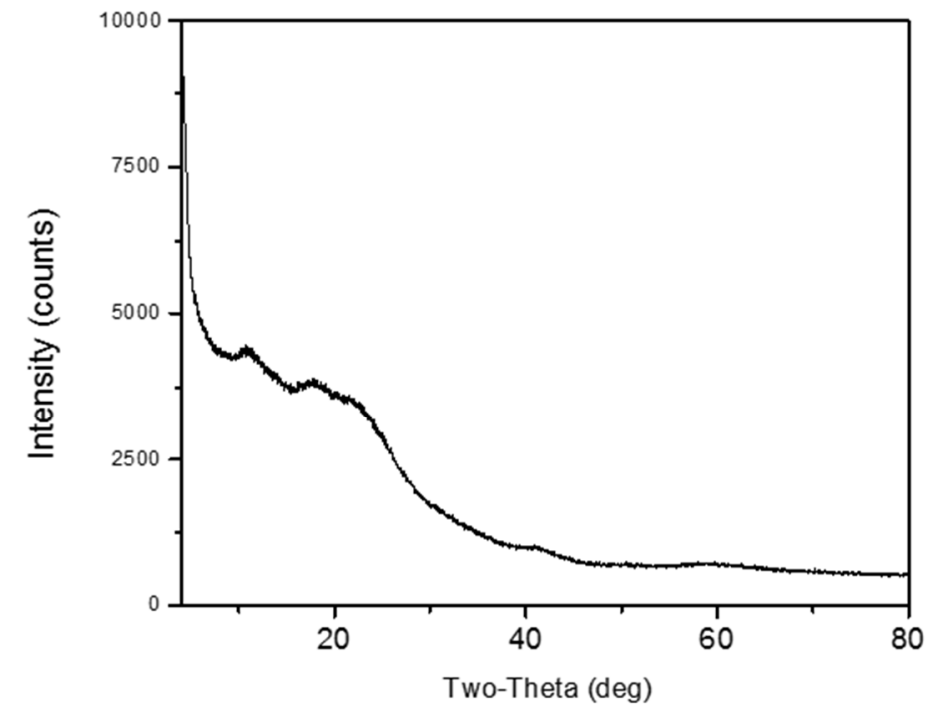

Figure S1: XRD diffraction pattern of COP-175 


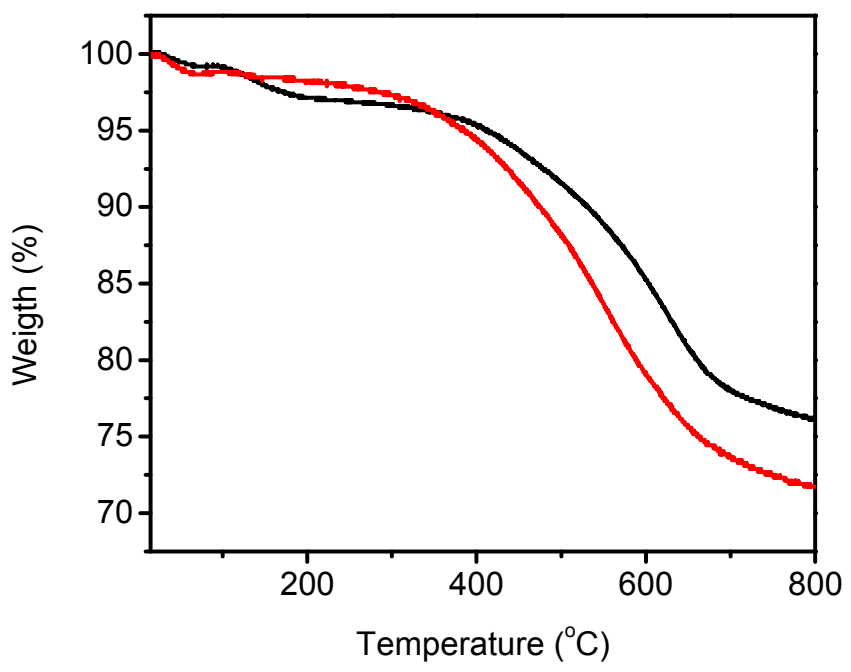

Figure S2: TGA of COP-175 and COP-175-MeO in nitrogen atmosphere

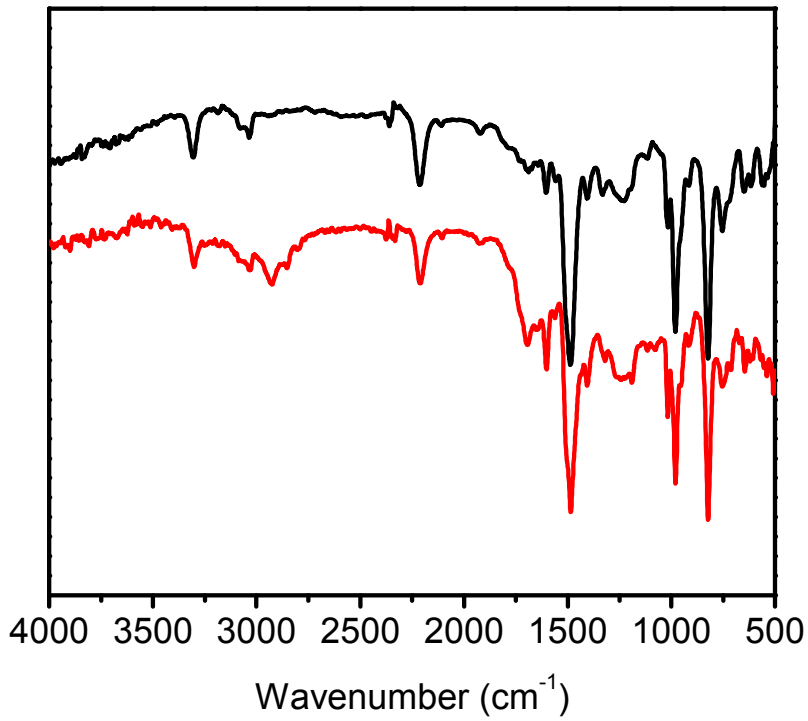

Figure S3. FTIR spectra of COP-175 (black) and COP-175-MeO (red).
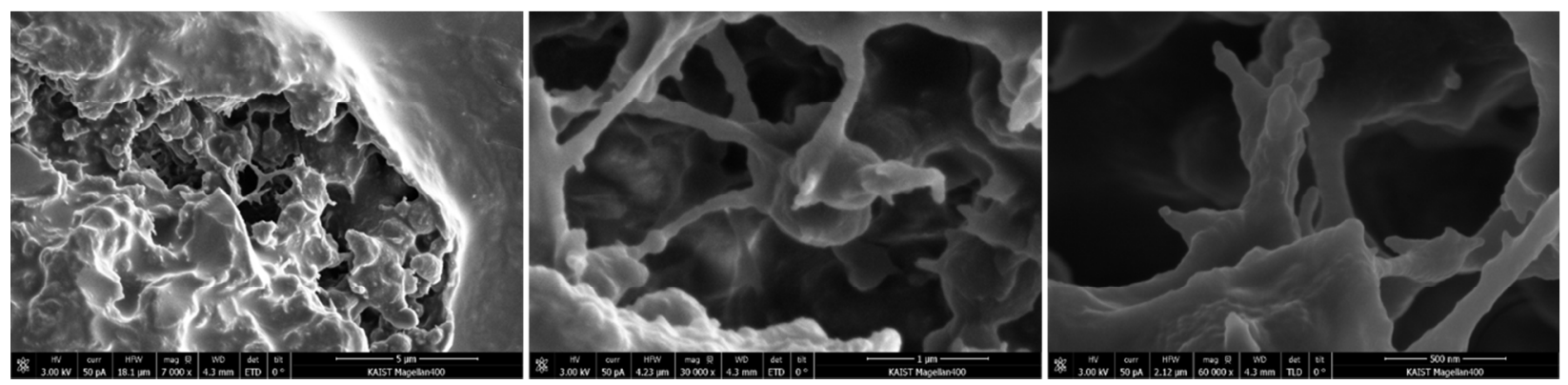
Figure S3: SEM images of COP-175 at $5 \mu \mathrm{m}, 1 \mu \mathrm{m}$ and $500 \mathrm{~nm}$ magnification

\section{REFERENCES}

S1. (a) Lu, W.; Yuan, D.; Zhao, D.; Schilling, C. I.; Plietzsch, O.; Muller, T.; Bräse, S.; Guenther, J.; Blümel, J.; Krishna, R.; Li, Z.; Zhou, H.-C., Porous Polymer Networks: Synthesis, Porosity, and Applications in Gas Storage/Separation. Chem. Mater. 2010, 22, 5964-5972; (b) Yuan, Y.; Ren, H.; Sun, F.; Jing, X.; Cai, K.; Zhao, X.; Wang, Y.; Wei, Y.; Zhu, G., Targeted Synthesis of a 3D Crystalline Porous Aromatic Framework with Luminescence Quenching Ability for Hazardous and Explosive Molecules. J. Phys. Chem. C 2012, 116, 26431-26435.

S2. Dutta, T.; Woody, K. B.; Watson, M. D., Transition-Metal-Free Synthesis of Poly(phenylene Ethynylene)s with Alternating Aryl-Perfluoroaryl Units. J. Am. Chem. Soc. 2008, 130, 452-453. 